\title{
A Four-Immune Gene Prognostic Risk Model for Colorectal Adenocarcinoma Based on the TCGA and ImmPort Data Sets
}

\section{Boyang Xu}

China Medical University Hospital https://orcid.org/0000-0002-0435-7117

\section{Ziqi Peng}

China Medical University Hospital

\section{Yue An}

China Medical University Hospital

\section{Xue Yao}

China Medical University Hospital

Mingjun Sun ( $2020110089 @ s t u . c m u . e d u . c n)$

the First Affiliated Hospital of China Medical University https://orcid.org/0000-0002-8852-5535

\section{Primary research}

Keywords: colorectal adenocarcinoma, immune gene, risk model, immune infiltration, prognosis

Posted Date: December 4th, 2020

DOl: https://doi.org/10.21203/rs.3.rs-120261/v1

License: (c) (i) This work is licensed under a Creative Commons Attribution 4.0 International License. Read Full License 


\section{Abstract}

Background: As one of the hot spots in oncology field, immune research provides new ideas for the diagnosis and treatment of tumors. Different histological types of colorectal cancer are different. Adenocarcinoma, as the type with the highest proportion, has a high research value. This study aims to build an immune gene prognostic risk model for colorectal adenocarcinoma to improve the diagnosis and prognosis prediction of colorectal adenocarcinoma.

Methods: The differentially expressed immune genes could be obtained from the gene expression data downloaded from The Cancer Genome Atlas (TCGA) and the immune gene data downloaded from the ImmPort Database. Univariate COX and multivariate COX analyses were used to construct the immune gene prognostic risk model of and the clinical application potential of this model. The correlation between the model and the immune cells infiltration and the influence of each immune cell on the survival were analyzed.

Results: 5975 differentially expressed genes were obtained, and 497 differentially expressed immune genes were selected by combining the information of immune genes. Among them, 36 immune genes were associated with prognosis, and 4 immune genes (THRB, IL1RL2, LGR6, LTB4R2) were included in the prognostic risk model of immune genes. Patients with higher Risk Score had shorter survival. Compared with gender, age and pathological stage, the model has better prediction potential. In addition, the model was correlated with Macrophages M0, Macrophages M1, T cells follicular helper and NK cells activated. Among them, $\mathrm{T}$ cells follicular helper and Macrophages M0 were related to the survival of patients.

Conclusion: We developed a prognostic risk model containing four immune genes, THRB, IL1RL2, LGR6 and LTB4R2, which accurately described the prognosis of the patient, and affected the survival of patients by influencing the infiltration of Macrophages $\mathrm{M} 0$ and $\mathrm{T}$ cells follicular helper.

\section{Background}

As one of the hot spots in oncology field, colorectal cancer seriously endangers human health. Its morbidity and mortality rank the third and the second respectively among all cancers, and the trend is increasing (1). There are many histological types of colorectal cancer, including adenocarcinoma, squamous cell carcinoma and undifferentiated carcinoma, etc. There are great differences in molecular structure, cell type and biological behavior among different histological types of colorectal cancer $(2,3)$. Adenocarcinoma, as the highest type, has a high research value.

Immune research, a hot spot in the field of cancer research, provides a new way for the diagnosis, treatment and prognosis assessment of malignant tumors. Studies have shown that low immune cytotoxicity and the absence of $\mathrm{T}$ cell infiltration are associated with poor prognosis in colon carcinoma patients $(4,5)$. In the immunotherapy of colorectal cancer, immune checkpoint inhibitors targeting PD-1 and CTLA-4 are very effective in advanced-stage, mismatch repair deficient (dMMR) colon cancers and has become the standard treatment for dMMR metastatic colorectal cancer (6-8). The protein encoded 
by immune gene CCR8 is a chemokine receptor mainly expressed on regulatory T cells (Tregs), which affects the regulation of monocyte chemotaxis and thymocyte apoptosis and is crucial for CCR8 + Tregmediated immune suppression (9). Studies have shown that CCR8 is highly specifically expressed in colon cancer, and inhibition of CCR8 can enhance anti-tumor immunity and prolong patient survival by regulating resident regulatory $T$ cells of the tumor (10).

With the progress of high-throughput gene sequencing technology, more and more genes have been put into practical use as specific therapeutic targets and prognostic markers for malignant tumors $(11,12)$. However, compared with other cancers, immune studies in colorectal cancer are still immature, and studies on specific immune genes and immune cell infiltration of colorectal adenocarcinoma are still to be explored. Therefore, this study constructed a reliable risk model based on differentially expressed immune genes in patients with colorectal adenocarcinoma and discussed the influence of this model on the immune cells infiltration in patients with colorectal adenocarcinoma and its clinical application potential.

\section{Material And Methods}

\section{Database download}

Transcriptome data and clinical data of all patients with colorectal adenocarcinoma were obtained from The TCGA database(https://portal.gdc.cancer.gov/). ImmPort (www.immport.org) database provides the data of immune genes.

\section{Identification of DE genes and DE immune genes}

Differentially expressed (DE) gene analysis was performed on transcriptome data through $\mathrm{R}$ package limma. Genes with |log2FC| $>1$ and Pvalue $<0.05$ were selected as DE genes for subsequent analysis. Based on the above DE genes and immune gene list, the differentially expressed immune genes were obtained. Heatmap and volcano map were drawn by Pheatmap package and Gplots package.

\section{Enrichment analysis of DE immune genes}

David(https://david.ncifcrf.gov/) website was used for Gene Ontology (GO) and Kyoto Encyclopedia of Genes and Genomes (KEGG) analysis. Terms with Pvalue $<0.05$ were considered to be significant.

\section{Construction and evaluation of prognostic risk models}

Based on DE immune genes and patients' survival time, univariate COX analysis was used to determine the DE immune genes associated with survival. Pvalue $<0.05$ were set as the cut-offs. Based on the above genes, multivariate COX analysis was used to determine the optimal prognostic risk model. The Risk Score is calculated based on Cox coefficient and gene expression, and the formula is as follows:

$\mathrm{N}$, Coei and Expi represent the number of genes, coefficient value and gene expression level, respectively. The cut-off value of Risk Score is the median. If the cut-off value is greater than or equal to the cut-off 
value, it is high risk, otherwise it is low risk. Survival package and Survminer package were used to analyze the survival of the two groups. Receiver operating characteristic (ROC) analysis was used to evaluate the accuracy of the model for predicting 3-year and 5-year survival. The area under the ROC curve (AUC) $>0.6$ is considered to have predictive value, while AUC $>0.75$ represents excellent predictive ability $(13,14)$.

\section{Clinical correlation analysis of the model}

Univariate and multivariate Cox analysis was used to show the relationship among Risk Score, gender, age, pathological stage and overall survival. Based on the gene expression data in the model and clinical data of patients, the relationship between each gene and patients' clinical variables was analyzed. The clinical features were grouped according to the following criteria: age ( $\leq 65$ and $>65$ years), gender (male and female), pathological stage (stage I\&II and stage III\&IV), T (T1-2 and T3-4), N (N0 and N1-3) and M ( $\mathrm{M} 0$ and $\mathrm{M} 1$ ).

\section{Relationship between model and immune cell infiltration}

The infiltration of 22 kinds of immune cells was analyzed by R-package Cibersort and the influence of different immune cells on survival was analyzed. Pearson correlation coefficient test was used to calculate the correlation between the Risk Score and immune cell infiltration.

\section{Results}

\section{Database download}

The transcriptome data of 39 normal tissues and 398 colon adenocarcinoma tissues were downloaded from TCGA database. Samples coming from the same patients with other samples and samples with short follow-up time (<90 days) were deleted. As a result, 234 samples were included in further analysis. The patients' clinical information is shown in Table 1. 
Table 1

Clinical information of the 234 colon carcinoma patients

\begin{tabular}{|c|c|c|c|}
\hline Clinical Features & Variable & $\mathrm{N}($ Total = 234) & Percentage (\%) \\
\hline \multirow[t]{2}{*}{ Survival } & Dead & 15 & 6.4 \\
\hline & Alive & 219 & 93.6 \\
\hline \multirow[t]{2}{*}{ Gender } & Male & 134 & 57.3 \\
\hline & Female & 100 & 42.7 \\
\hline \multirow[t]{2}{*}{ Age } & $>65$ & 132 & 56.4 \\
\hline & $<=65$ & 102 & 43.6 \\
\hline \multirow[t]{4}{*}{ Pathological stage } & Stage I & 50 & 21.4 \\
\hline & Stage II & 95 & 40.6 \\
\hline & Stage III & 67 & 28.6 \\
\hline & Stage IV & 22 & 9.4 \\
\hline $\mathrm{T}$ & $\mathrm{T} 1$ & 6 & 2.6 \\
\hline$N$ & $\mathrm{~T} 2$ & 50 & 21.4 \\
\hline \multirow[t]{7}{*}{ M } & T3 & 161 & 68.8 \\
\hline & T4 & 17 & 7.3 \\
\hline & NO & 147 & 62.8 \\
\hline & N1 & 56 & 23.9 \\
\hline & N2 & 31 & 13.2 \\
\hline & MO & 212 & 90.6 \\
\hline & M1 & 22 & 9.4 \\
\hline
\end{tabular}

Through Wilcoxon test, 5975 DE genes were screened, including 3799 genes with high expression and 2176 genes with low DE expression. According to the above DE genes and 1811 immune gene information downloaded from Immport database, 497 DE immune genes were selected, including 168 high expression genes and 329 low expression genes. The top ten DE immune genes with high and low expression are shown in Table 2. The expression of DE gene and DE immune gene in normal and cancer tissues were shown by heatmap (Fig. $1 A$ and $B$ ), while the distribution of DE genes and DE immune genes in $\log _{2} \mathrm{FC}$ and $\log _{10}$ Pvalue were shown by volcano map (Fig. $1 \mathrm{C}$ and D). 
Table 2

The top 10 up-regulated and down-regulated DE immune genes

\begin{tabular}{|llll|}
\hline Group & Gene & LogFC & P adjust \\
\hline Up-regulated & PPBP & 9.728897343 & $3.97 \mathrm{E}-12$ \\
& OBP2B & 8.086832175 & $2.06 \mathrm{E}-09$ \\
& CST4 & 7.182526340 & $1.48 \mathrm{E}-17$ \\
& S100A7 & 6.146141749 & $1.82 \mathrm{E}-05$ \\
\hline & FGF20 & 6.122990834 & $1.12 \mathrm{E}-06$ \\
& ORM1 & 5.980091181 & $1.59 \mathrm{E}-06$ \\
& ESM1 & 5.86065201 & $4.40 \mathrm{E}-21$ \\
\hline AMELX & 5.785542368 & $5.29 \mathrm{E}-15$ \\
\hline CXCL17 & 5.587610367 & $3.36 \mathrm{E}-11$ \\
\hline Down-regulated & SLC10A2 & -7.047820314 & $3.09 \mathrm{E}-22$ \\
\hline INSL5 & -6.044940761 & $4.11 \mathrm{E}-17$ \\
\hline GCG & -5.892104301 & $4.40 \mathrm{E}-21$ \\
\hline SST & -5.710334384 & $4.40 \mathrm{E}-21$ \\
\hline PYY & -5.540414355 & $4.58 \mathrm{E}-21$ \\
\hline CHGA & -4.969225652 & $4.40 \mathrm{E}-21$ \\
\hline GUCA2A & -4.920266692 & $5.34 \mathrm{E}-21$ \\
\hline BMP3 & -4.901576421 & $4.40 \mathrm{E}-21$ \\
\hline ANGPTL7 & -4.814529986 & $4.58 \mathrm{E}-21$ \\
\hline ANGPTL1 & -3.895992141 & $7.37 \mathrm{E}-20$ \\
\hline
\end{tabular}

\section{Function and pathway enrichment analysis of immune genes}

BP and KEGG analysis showed that DE immune genes mainly influenced tumor and immune-related processes and pathways. The top ten BP and KEGG terms were shown in Fig. 1E and F (Tables 3 and 4). 


\begin{tabular}{|llll|}
\hline Description & Count & GENERATIO & P adjust \\
\hline Immune response & 121 & $121 / 497$ & $1.90 \mathrm{E}-98$ \\
\hline Signal transduction & 80 & $80 / 497$ & $5.91 \mathrm{E}-18$ \\
\hline Inflammatory response & 70 & $70 / 497$ & $2.51 \mathrm{E}-41$ \\
\hline Regulation of immune response & 62 & $62 / 497$ & $2.11 \mathrm{E}-54$ \\
\hline Receptor-mediated endocytosis & 59 & $59 / 497$ & $5.36 \mathrm{E}-49$ \\
\hline Proteolysis & 58 & $58 / 497$ & $2.55 \mathrm{E}-23$ \\
\hline G-protein coupled receptor signaling pathway & 58 & $58 / 497$ & $1.05 \mathrm{E}-11$ \\
Complement activation, classical pathway & 57 & $57 / 497$ & $1.90 \mathrm{E}-65$ \\
Fc-gamma receptor signaling pathway involved in phagocytosis & 54 & $54 / 497$ & $1.10 \mathrm{E}-52$ \\
OFc-epsilon receptor signaling pathway & 53 & $53 / 497$ & $2.71 \mathrm{E}-42$ \\
\hline
\end{tabular}

Table 4

Top ten KEGG terms

\begin{tabular}{|llll|}
\hline Description & Count & GENERATIO & P adjust \\
\hline Cytokine-cytokine receptor interaction & 80 & $80 / 497$ & $9.97 \mathrm{E}-60$ \\
\hline Pathways in cancer & 38 & $38 / 497$ & $8.09 \mathrm{E}-09$ \\
\hline Chemokine signaling pathway & 36 & $36 / 497$ & $2.19 \mathrm{E}-17$ \\
\hline PI3K-Akt signaling pathway & 32 & $32 / 497$ & $4.34 \mathrm{E}-07$ \\
\hline Rap1 signaling pathway & 30 & $30 / 497$ & $5.68 \mathrm{E}-11$ \\
\hline Ras signaling pathway & 29 & $29 / 497$ & $1.62 \mathrm{E}-09$ \\
\hline Neuroactive ligand-receptor interaction & 26 & $26 / 497$ & $5.76 \mathrm{E}-06$ \\
Natural killer cell mediated cytotoxicity & 26 & $26 / 497$ & $1.62 \mathrm{E}-13$ \\
Jak-STAT signaling pathway & 18 & $18 / 497$ & $6.59 \mathrm{E}-06$ \\
Rheumatoid arthritis & 18 & $18 / 497$ & $3.83 \mathrm{E}-09$ \\
\hline
\end{tabular}

\section{Construction of prognostic risk model}

Univariate Cox analysis was used to screen for DE immune genes related to patient survival. Pvalue < 0.05 was used as cutoff value, and a total of 36 genes were obtained (Fig. 2A). By multivariate Cox analysis, four high-risk immune genes were obtained (Fig. 2B), including thyroid hormone receptor beta (THRB), interleukin 1 receptor like 2 (IL1RL2), leucine rich repeat containing G protein coupled receptor 6 
(LGR6) and leukotriene B4 receptor 2 (LTB4R2). The formula of Risk Score is as follows: Risk Score = $(0.924903748 \times \operatorname{Exp}$ of THRB $)+(0.443400271 \times \operatorname{Exp}$ of IL1RL2 $)+(0.053843604 \times \operatorname{Exp}$ of LGR6 $)+$ $(0.428025347 \times$ Exp of LTB4R2). Median Risk Score was set as the cut-off value and the patients were divided into high-risk and low-risk group. There was a significant difference in survival between two groups (Pvalue $=1.625 \mathrm{e}-03$ ) (Fig. $2 \mathrm{C}$ ). The ROC curves show that the AUC values of the model in 3 years and 5 years are 0.731 and 0.827 respectively, which shows that this model has good prediction ability (Fig. 2D). The heatmap of gene expression, Risk Score distribution map and survival state map of the two groups are shown in Fig. 2E, Fig. 3A and Fig. 3B.

\section{Independent prognostic ability of the model}

According to univariate COX and multivariate Cox analyses, the survival of patients with colorectal adenocarcinoma was correlated with Risk Score and pathological stage (Fig. $3 \mathrm{C}$ and D). Among them, the Pvalue of Risk Score $=0.004$ and AUC of 5 years $=0.800$, which has good independent prediction ability (Fig. 3E).

\section{Correlation between genes in model and clinical characteristics}

With the increase of THRB expression, $\mathrm{N}$ stage and pathological stage showed an increasing trend (Fig. 4B and C). LGR6 had the same relationship with age, $M$ stage and pathological stage (Fig. 4D and F). In addition, IL1RL2 was positively correlated with age (Fig. 4A).

\section{Relationship between model and immune cell infiltration}

The infiltration of 22 kinds of immune cells (Fig. 5A) was analyzed. Among them, the infiltration of 16 kinds of immune cells were different between the colorectal adenocarcinoma tissues and normal tissues (Fig. 5B). The correlations between different immune cells are shown in Fig. 5C. Macrophages M0 was positively correlated with Risk Score $(r=0.247, P=0.013)$, while Macrophages M1 $(r=-0.213, P=0.032)$, NK cells activated $(r=-0.206, P=0.039)$ and $T$ cells follicular helper $(r=-0.310, P=0.002)$ were negatively correlated with Risk Score (Fig. 6A-D). In the survival analysis of the above four kinds of cells, Macrophages M0 was negatively correlated with survival, while T cells follicular helper showed a positive correlation (Fig. 6E and F), which suggested that the model might affect the survival of patients by affecting the infiltration of Macrophages $\mathrm{M} 0$ and $\mathrm{T}$ cells follicular helper in patients with colorectal adenocarcinoma.

\section{Discussion}

As a malignant tumor with a morbidity of second and a mortality rate of third, there are about 1.8 million new cases of colorectal cancer in 2018 and caused about 550000 deaths (1). Therefore, the research on colorectal cancer needs further study. Studies have shown that the immune system greatly influences the occurrence and development of tumors, immunotherapy for tumors is also more and more put into 
clinical application and achieved good results (15-17). However, as the largest histological type of colorectal cancer, the specific immune research on colorectal adenocarcinoma is still scarce, so the influence of immune genes and immune cells on colorectal adenocarcinoma has high research value. In this study, we developed a four-gene prognostic risk model for colorectal adenocarcinoma that can be used as an independent risk predictor of patient survival. Compared with age, gender and pathological stage, this model has higher prediction accuracy. Immune cell infiltration analysis also showed that two kinds of immune cells related to survival were correlated with the model, which suggested that this model could affect the patients' prognosis through immune infiltration.

In the analysis of differentially expressed genes between normal tissues and adenocarcinoma tissues, 497 immune genes were obtained. Enrichment analysis of BP and KEGG pathways showed that these genes affected immune response, signal transduction and other biological processes, as well as cytokinecytokine receptor interaction, chemokine signaling pathway and other pathways. These provide some reference for further basic experiments. Among them, 36 immune genes were associated with survival. Finally, four ideal immune genes (THRB, IL1RL2, LGR6 and LTB4R2) were included in the risk model. The protein encoded by THRB is one of the receptors of thyroid hormone, which mediates the biological activity of thyroid hormone (18). Studies have shown that the expression of THRB in the nucleus represents the poor prognosis of breast carcinoma patients (19). IL1RL2 was expressed in intestinal T lymphocytes, which induced the proliferation of CD4 + lymphocytes, and low expressed in colon of patients with Hirschsprung's disease, resulting in increased inflammation and changes in mucosal healing $(20,21)$. LGR6 encodes a glycoprotein hormone receptor, which is highly expressed in colon carcinoma and has tumor promoting effect. It can be used as an independent risk factor and a biomarker for the diagnosis and prognosis of colon carcinoma $(22,23)$. LTB4R2, a member of the G protein-coupled receptor (GPCR) family, greatly influences the progresses of many diseases including tumor and asthma $(24,25)$. Research has shown that LTB4R2 promoted the invasion and metastasis of bladder carcinoma through a reactive oxygen species-linked pathway (26).

To estimate the risk predictive capacity of the model, we used the univariate COX analysis to calculate the correlations among clinical variables, Risk Score and survival. The results showed that pathological stage and Risk Score could be regarded as independent risk predictors. Further multivariate Cox analysis showed compared to other clinical variables, the Risk Score had more satisfying predictive ability. Besides, the genes in this risk model were also correlated with clinical parameters. With the increase of age, the expression of IL1RL2 increased. Meanwhile, THRB was positively correlated with N stage and pathological stage. LGR6 showed the same relationship with age, M stage and pathological stage.

Immune cells infiltration is an important part of tumor immunity, which affects the treatment and prognosis of various cancers (27-29). In this study, we found that the Risk Score of the model was correlated with four kinds of immune cells, in which Macrophages M0 was positively correlated, while Macrophages M1, T cells follicular helper and NK cells activated were negatively correlated. Survival analysis showed that the high expression of Macrophages M0 represents the poor prognosis of the patients, while the higher level of T cells follicular helper represents a longer survival. Qun Zhang et al. 
reported that in ovarian cancer, the apoptosis of tumor cells stimulated the differentiation of Macrophages $\mathrm{M} 0$ to $\mathrm{M} 2$, and promoted the proliferation and migration of tumor, which provided a possible chemotherapy scheme for patients with ovarian cancer (30). In addition, higher T cells follicular helper represent a better prognosis in patients with colon and breast cancer (31-33). In this study, high Risk Score represent higher Macrophages M0 and lower T cells follicular helper levels, which have adverse effects on the survival of patients. However, the model derived from this analysis needs to be further verified by clinical samples and basic experiments to obtain the exact impact of the model on the prognosis of patients with colorectal adenocarcinoma.

\section{Conclusion}

We developed and validated a four-immune gene model of colorectal adenocarcinoma, including THRB, IL1RL2, LGR6 and LTB4R2. This model could be used as an instrumental variable in the prognosis prediction of colorectal adenocarcinoma.

\section{Abbreviations}

DE, Differentially expressed; TCGA, The Cancer Genome Atlas; FC, Fold Change; BP, Biological process; KEGG, Kyoto Encyclopedia of Genes and Genomes; ROC, Receiver operating characteristic; AUC, Area under the curve

\section{Declarations}

\section{Ethics approval and consent to participate}

Not applicable.

\section{Consent for publication}

Not applicable.

\section{Availability of data and materials}

The data used to support the findings of this study are included within the article. The data and materials in the current study are available from the corresponding author on reasonable request.

\section{Competing interests}

The authors declare no conflicts of interest. 


\section{Funding}

Not applicable.

\section{Authors' contributions}

MS conceived this research. BX implemented the bioinformatics analysis and drafted the manuscript. ZP, YA and XY provided guidance to the study. All authors read and approved the final manuscript.

\section{Acknowledgements}

Not applicable.

\section{Authors' information}

Affiliations

Department of Gastroenterology, the First Affiliated Hospital of China Medical University, Shenyang, China Boyang Xu, Yue An \& Mingjun Sun

Department of Breast Surgery, the First Affiliated Hospital of China Medical University, Shenyang, China

Ziqi Peng

Department of Surgical Oncology, the First Hospital of China Medical University, Shenyang, China Xue Yao

\section{References}

1. Bray F, Ferlay J, Soerjomataram I, Siegel RL, Torre LA, Jemal A. Global cancer statistics 2018: GLOBOCAN estimates of incidence and mortality worldwide for 36 cancers in 185 countries. CA Cancer J Clin. 2018;68(6):394-424.

2. Lundquest DE, Marcus JN, Thorson AG, Massop D. Primary squamous cell carcinoma of the colon arising in a villous adenoma. Hum Pathol. 1988;19(3):362-4.

3. Shiiki S. [Undifferentiated carcinoma(endocrine cell carcinoma) of the colon]. Nihon Rinsho. 2004;62(5):979- 82. 
4. Mlecnik B, Bindea G, Kirilovsky A, Angell HK, Obenauf AC, Tosolini M, et al. The tumor microenvironment and Immunoscore are critical determinants of dissemination to distant metastasis. Sci Transl Med. 2016;8(327):327ra26.

5. Galon J, Costes A, Sanchez-Cabo F, Kirilovsky A, Mlecnik B, Lagorce-Pages C, et al. Type, density, and location of immune cells within human colorectal tumors predict clinical outcome. Science. 2006;313(5795):1960-4.

6. Overman MJ, Lonardi S, Wong KYM, Lenz HJ, Gelsomino F, Aglietta M, et al. Durable Clinical Benefit With Nivolumab Plus Ipilimumab in DNA Mismatch Repair-Deficient/Microsatellite Instability-High Metastatic Colorectal Cancer. J Clin Oncol. 2018;36(8):773-9.

7. Overman MJ, McDermott R, Leach JL, Lonardi S, Lenz HJ, Morse MA, et al. Nivolumab in patients with metastatic DNA mismatch repair-deficient or microsatellite instability-high colorectal cancer (CheckMate 142): an open-label, multicentre, phase 2 study. Lancet Oncol. 2017;18(9):1182-91.

8. Diaz LA, Jr., Le DT. PD-1 Blockade in Tumors with Mismatch-Repair Deficiency. N Engl J Med. 2015;373(20):1979.

9. Iellem A, Mariani M, Lang R, Recalde H, Panina-Bordignon P, Sinigaglia F, et al. Unique chemotactic response profile and specific expression of chemokine receptors CCR4 and CCR8 by CD4(+)CD25(+) regulatory T cells. J Exp Med. 2001;194(6):847 - 53.

10. Villarreal DO, L'Huillier A, Armington S, Mottershead C, Filippova EV, Coder BD, et al. Targeting CCR8 Induces Protective Antitumor Immunity and Enhances Vaccine-Induced Responses in Colon Cancer. Cancer Res. 2018;78(18):5340-8.

11. Kohne $\mathrm{CH}$. Successes and limitations of targeted cancer therapy in colon cancer. Prog Tumor Res. 2014;41:36-50.

12. Yang $\mathrm{C}$, Zhang $\mathrm{Y}, \mathrm{Xu} X$, Li W. Molecular subtypes based on DNA methylation predict prognosis in colon adenocarcinoma patients. Aging (Albany NY). 2019;11(24):11880-92.

13. Wan B, Liu B, Huang Y, Yu G, Lv C. Prognostic value of immune-related genes in clear cell renal cell carcinoma. Aging (Albany NY). 2019;11(23):11474-89.

14. Han ME, Kim JY, Kim GH, Park SY, Kim YH, Oh SO. SAC3D1: a novel prognostic marker in hepatocellular carcinoma. Sci Rep. 2018;8(1):15608.

15. Hamid O, Robert C, Daud A, Hodi FS, Hwu WJ, Kefford R, et al. Safety and tumor responses with lambrolizumab (anti-PD-1) in melanoma. N Engl J Med. 2013;369(2):134 - 44.

16. Restifo NP, Dudley ME, Rosenberg SA. Adoptive immunotherapy for cancer: harnessing the $T$ cell response. Nat Rev Immunol. 2012;12(4):269 - 81. 
17. Desrichard A, Snyder A, Chan TA. Cancer Neoantigens and Applications for Immunotherapy. Clin Cancer Res. 2016;22(4):807 - 12.

18. Flamant F, Gauthier K. Thyroid hormone receptors: the challenge of elucidating isotype-specific functions and cell-specific response. Biochim Biophys Acta. 2013;1830(7):3900-7.

19. Shao W, Kuhn C, Mayr D, Ditsch N, Kailuweit M, Wolf V, et al. Cytoplasmic and Nuclear Forms of Thyroid Hormone Receptor beta1 Are Inversely Associated with Survival in Primary Breast Cancer. Int J Mol Sci. 2020;21(1).

20. Penha R, Higgins J, Mutamba S, Barrow P, Mahida Y, Foster N. IL-36 receptor is expressed by human blood and intestinal T lymphocytes and is dose-dependently activated via IL-36beta and induces CD4 + lymphocyte proliferation. Cytokine. 2016;85:18-25.

21. Tomuschat C, O'Donnell AM, Coyle D, Puri P. Altered expression of IL36gamma and IL36 receptor (IL1RL2) in the colon of patients with Hirschsprung's disease. Pediatr Surg Int. 2017;33(2):181-6.

22. Chiang N, Libreros S, Norris PC, de la Rosa X, Serhan CN. Maresin 1 activates LGR6 receptor promoting phagocyte immunoresolvent functions. J Clin Invest. 2019;129(12):5294 - 311.

23. Wang W, Ding S, Zhang H, Li J, Zhan J, Zhang H. G protein-coupled receptor LGR6 is an independent risk factor for colon adenocarcinoma. Front Med. 2019;13(4):482 - 91.

24. Liu M, Shen J, Yuan H, Chen F, Song H, Qin H, et al. Leukotriene B4 receptor 2 regulates the proliferation, migration, and barrier integrity of bronchial epithelial cells. J Cell Physiol. 2018;233(8):611724.

25. Park J, Jang JH, Park GS, Chung Y, You HJ, Kim JH. BLT2, a leukotriene B4 receptor 2, as a novel prognostic biomarker of triple-negative breast cancer. BMB Rep. 2018;51(8):373-7.

26. Kim EY, Seo JM, Kim C, Lee JE, Lee KM, Kim JH. BLT2 promotes the invasion and metastasis of aggressive bladder cancer cells through a reactive oxygen species-linked pathway. Free Radic Biol Med. 2010;49(6):1072-81.

27. Sokratous G, Polyzoidis S, Ashkan K. Immune infiltration of tumor microenvironment following immunotherapy for glioblastoma multiforme. Hum Vaccin Immunother. 2017;13(11):2575-82.

28. Blanc C, Hans S, Tran T, Granier C, Saldman A, Anson M, et al. Targeting Resident Memory T Cells for Cancer Immunotherapy. Front Immunol. 2018;9:1722.

29. Tanaka A, Sakaguchi S. Targeting Treg cells in cancer immunotherapy. Eur J Immunol. 2019;49(8):1140-6. 
30. Zhang Q, Li H, Mao Y, Wang X, Zhang X, Yu X, et al. Apoptotic SKOV3 cells stimulate M0 macrophages to differentiate into M2 macrophages and promote the proliferation and migration of ovarian cancer cells by activating the ERK signaling pathway. Int J Mol Med. 2020;45(1):10-22.

31. Bindea G, Mlecnik B, Tosolini M, Kirilovsky A, Waldner M, Obenauf AC, et al. Spatiotemporal dynamics of intratumoral immune cells reveal the immune landscape in human cancer. Immunity. 2013;39(4):782 95.

32. Gu-Trantien C, Loi S, Garaud S, Equeter C, Libin M, de Wind A, et al. CD4(+) follicular helper T cell infiltration predicts breast cancer survival. J Clin Invest. 2013;123(7):2873-92.

33. Hollern DP, Xu N, Thennavan A, Glodowski C, Garcia-Recio S, Mott KR, et al. B Cells and T Follicular Helper Cells Mediate Response to Checkpoint Inhibitors in High Mutation Burden Mouse Models of Breast Cancer. Cell. 2019;179(5):1191 - 206 e21.

\section{Figures}

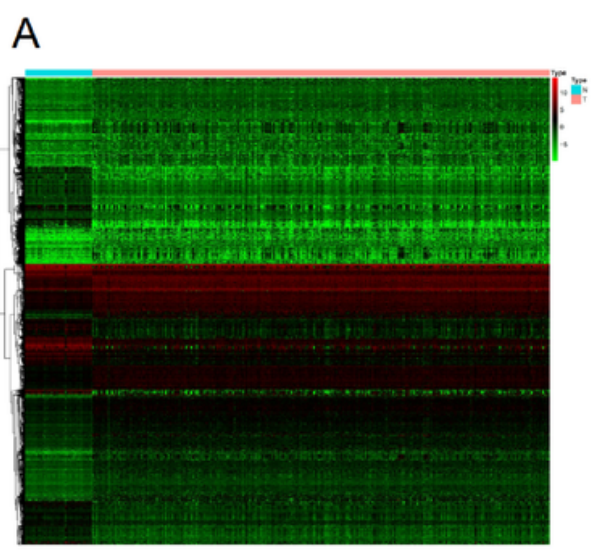

B

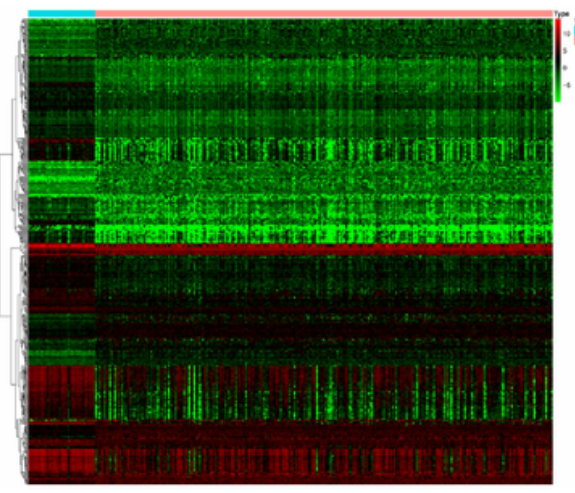

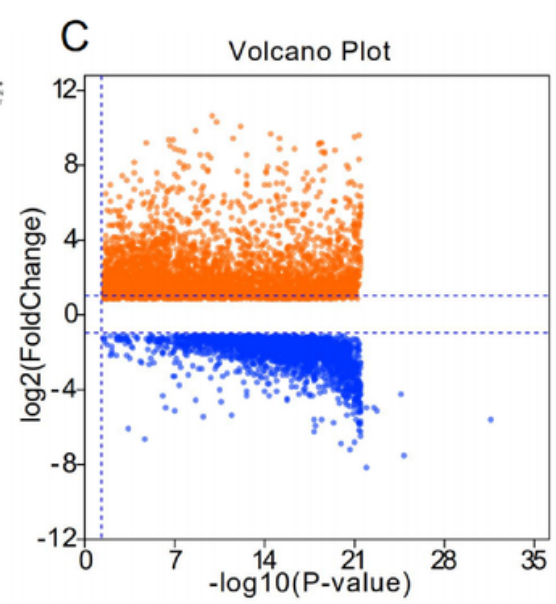

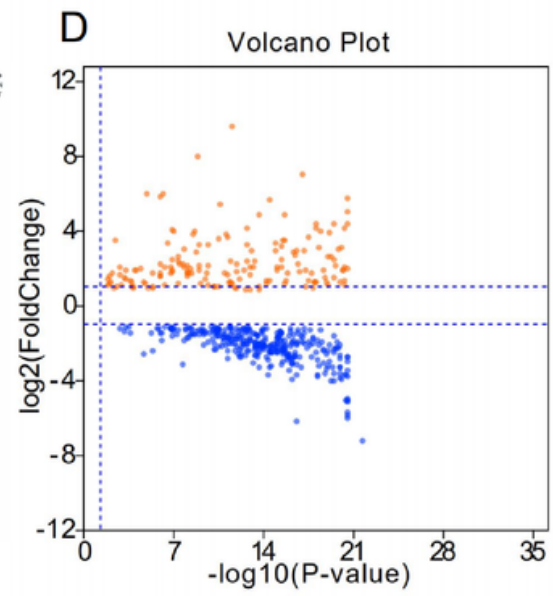

$E$

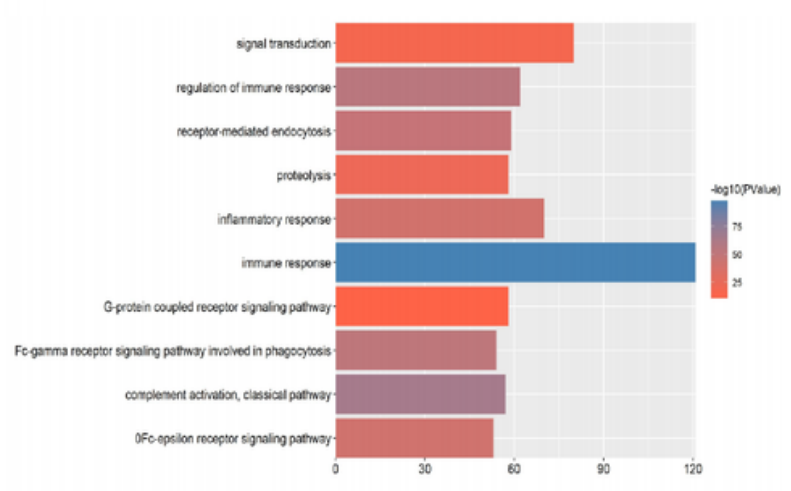

$\mathrm{F}$

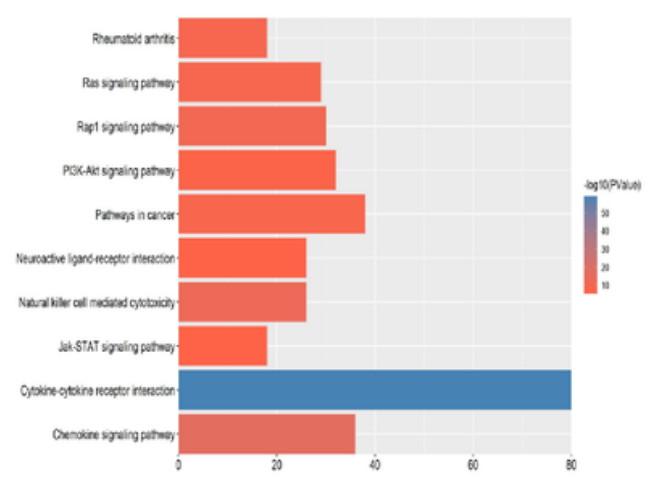

Figure 1

Determination of DE gene and DE immune gene A Heat map of the DE genes; $B$ Heatmap of the DE immune genes; C Volcano plot of the DE genes; D Volcano plot of the DE immune genes; E Biological 
process (BP) terms of the DE immune genes; F Kyoto Encyclopedia of Genes and Genomes (KEGG) analysis of the DE immune genes
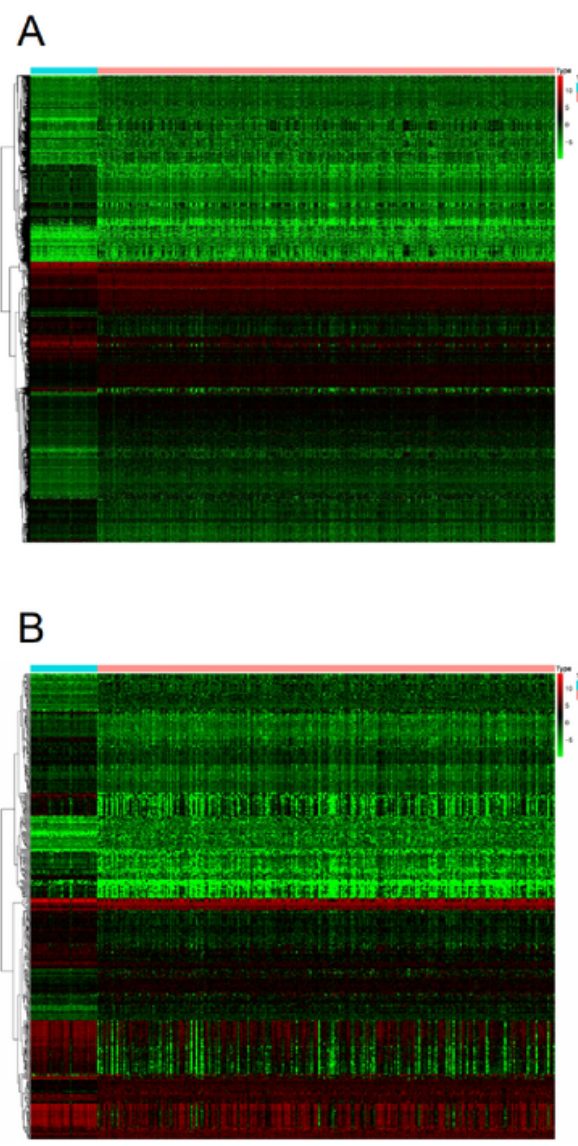
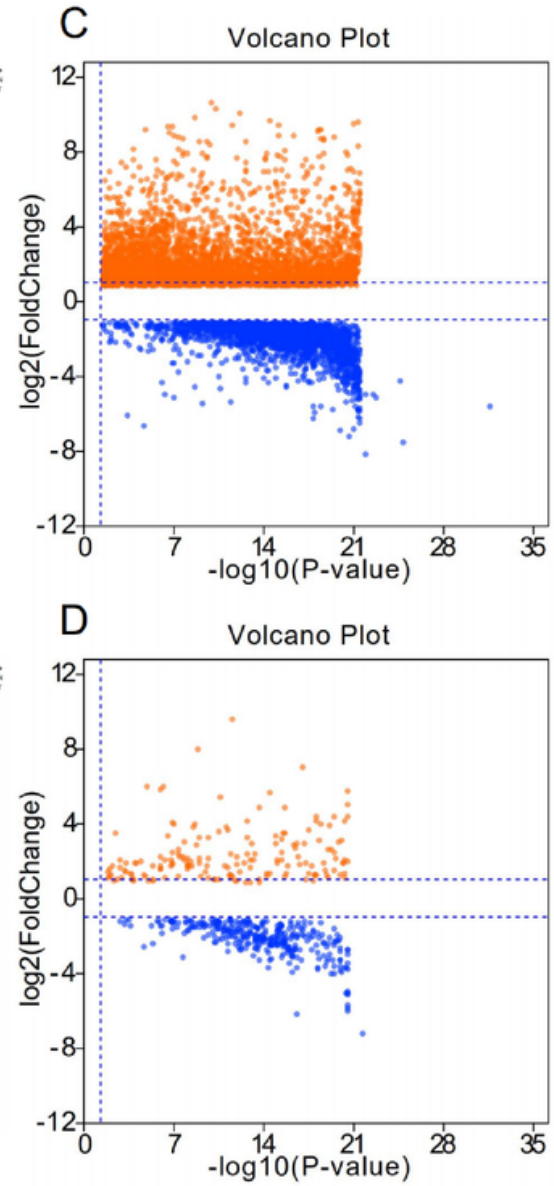

E
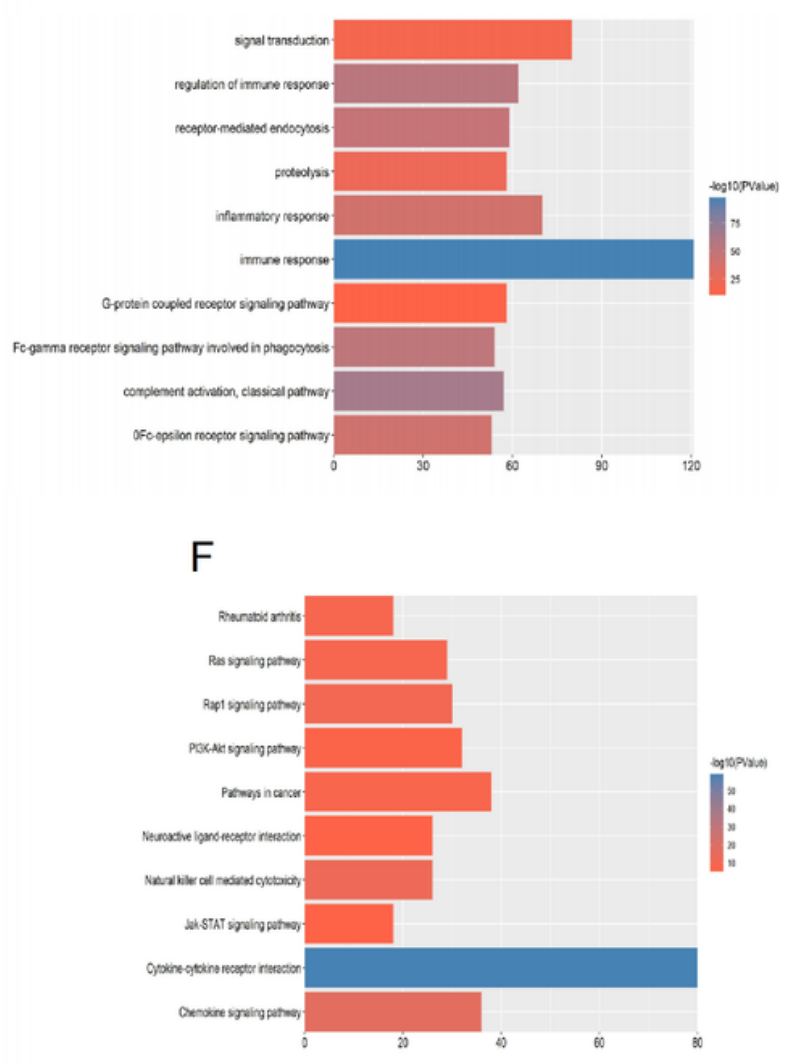

\section{Figure 1}

Determination of DE gene and DE immune gene A Heat map of the DE genes; $B$ Heatmap of the DE immune genes; $C$ Volcano plot of the DE genes; D Volcano plot of the DE immune genes; $E$ Biological process (BP) terms of the DE immune genes; F Kyoto Encyclopedia of Genes and Genomes (KEGG) analysis of the DE immune genes 
A

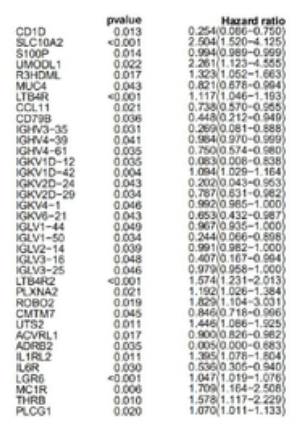

C

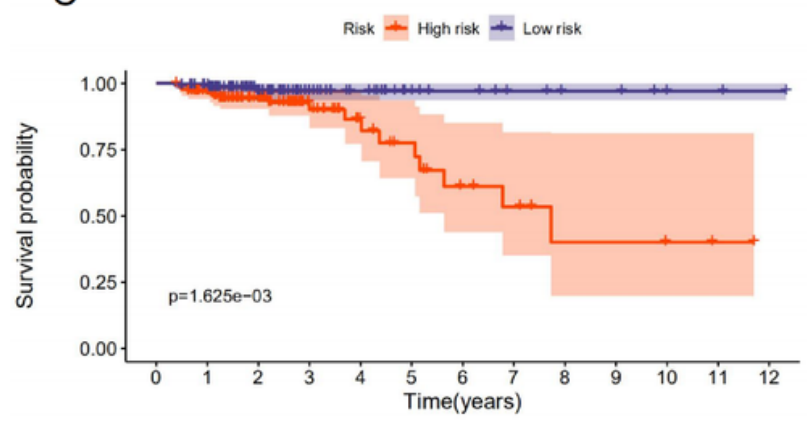

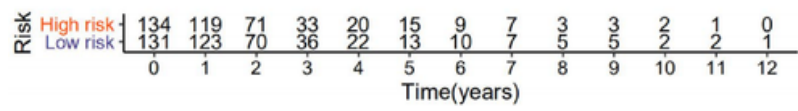

B

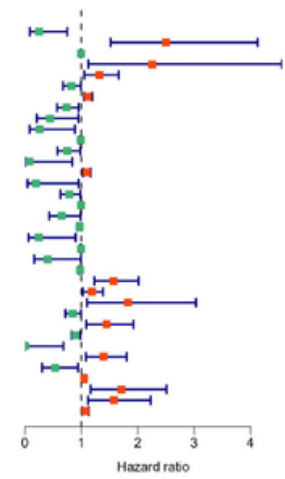

Risk + High risk + Low risk

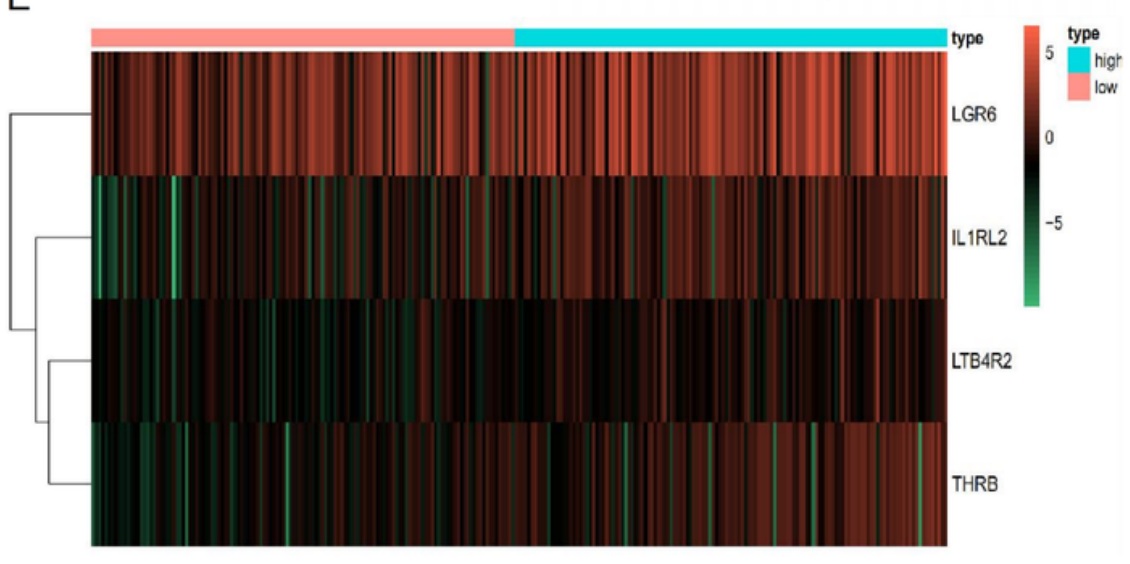

\section{Figure 2}

Construction and evaluation of prognostic risk model A Univariate Cox analysis; B Multivariate Cox analysis; C Survival analysis; D Time-dependent receiver operating characteristic (ROC) curve analysis; E Heatmap of risk genes 
A

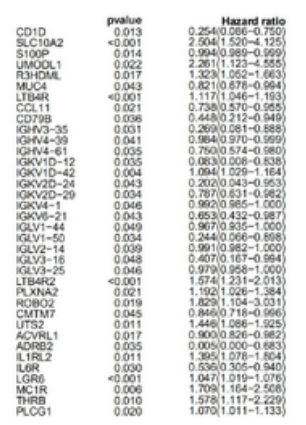

C

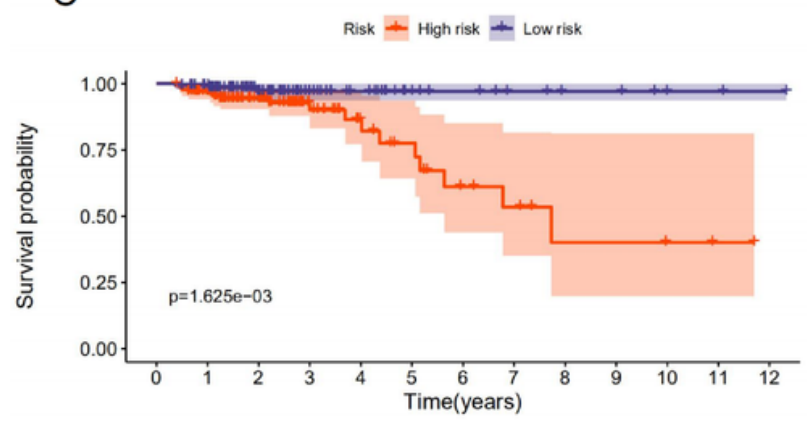

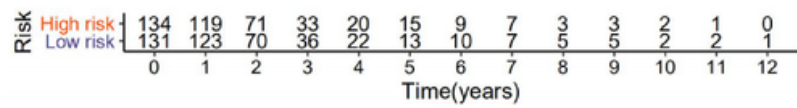

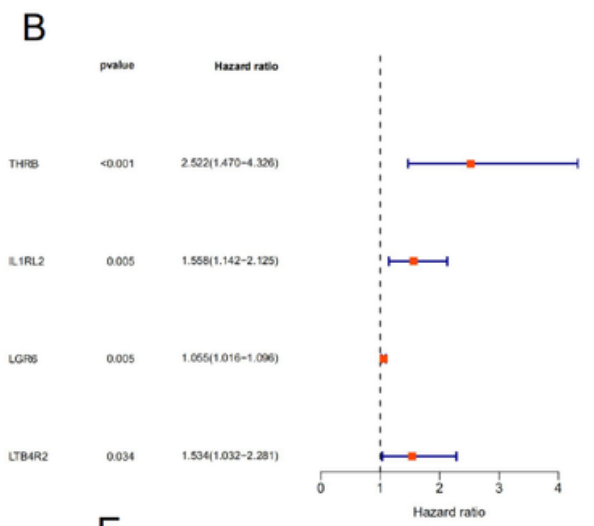

E

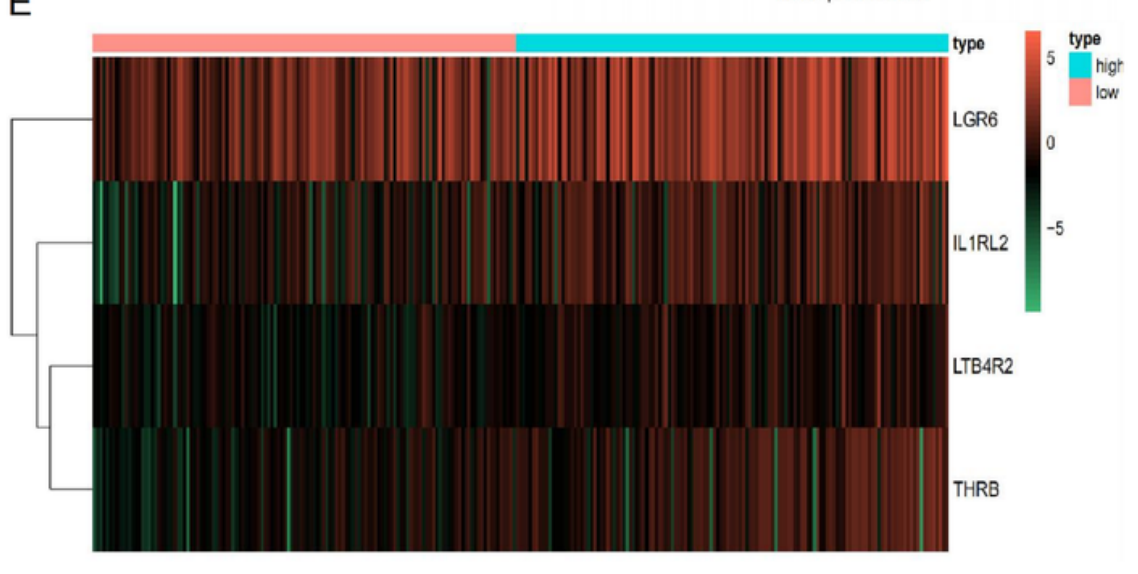

Figure 2

Construction and evaluation of prognostic risk model A Univariate Cox analysis; B Multivariate Cox analysis; C Survival analysis; D Time-dependent receiver operating characteristic (ROC) curve analysis; E Heatmap of risk genes 
A

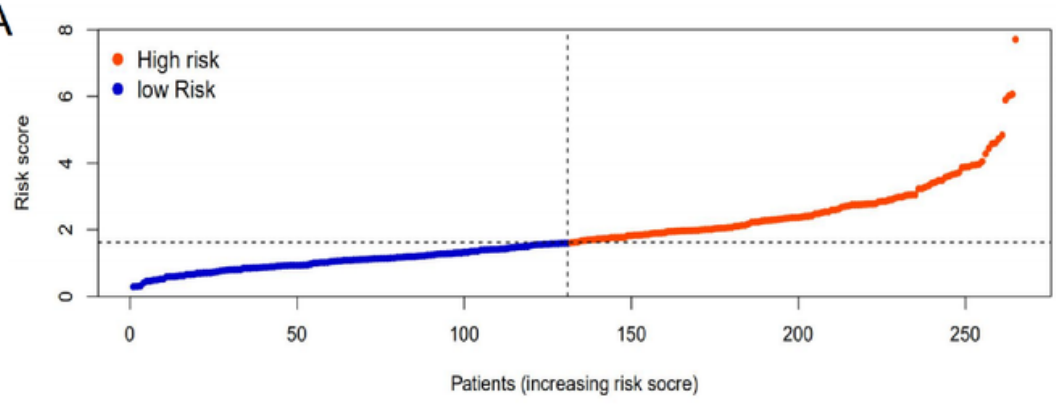

B

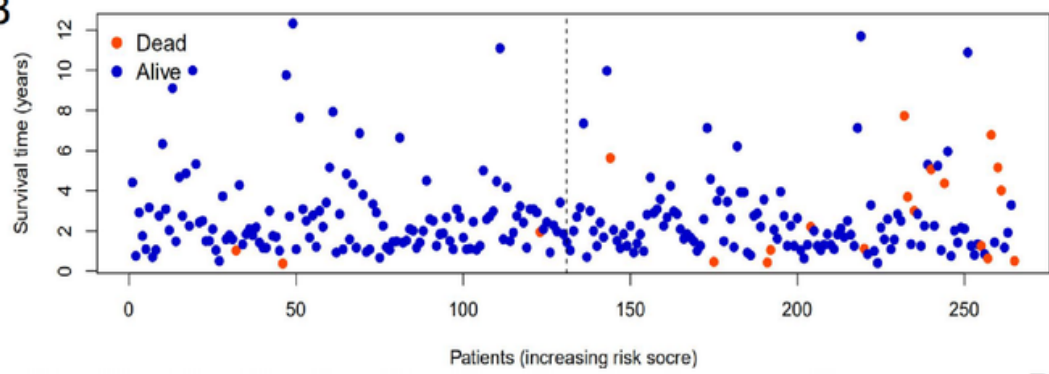

C
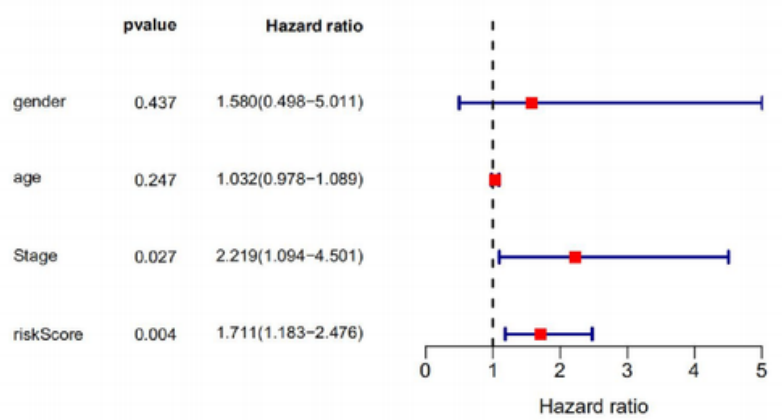

$E$
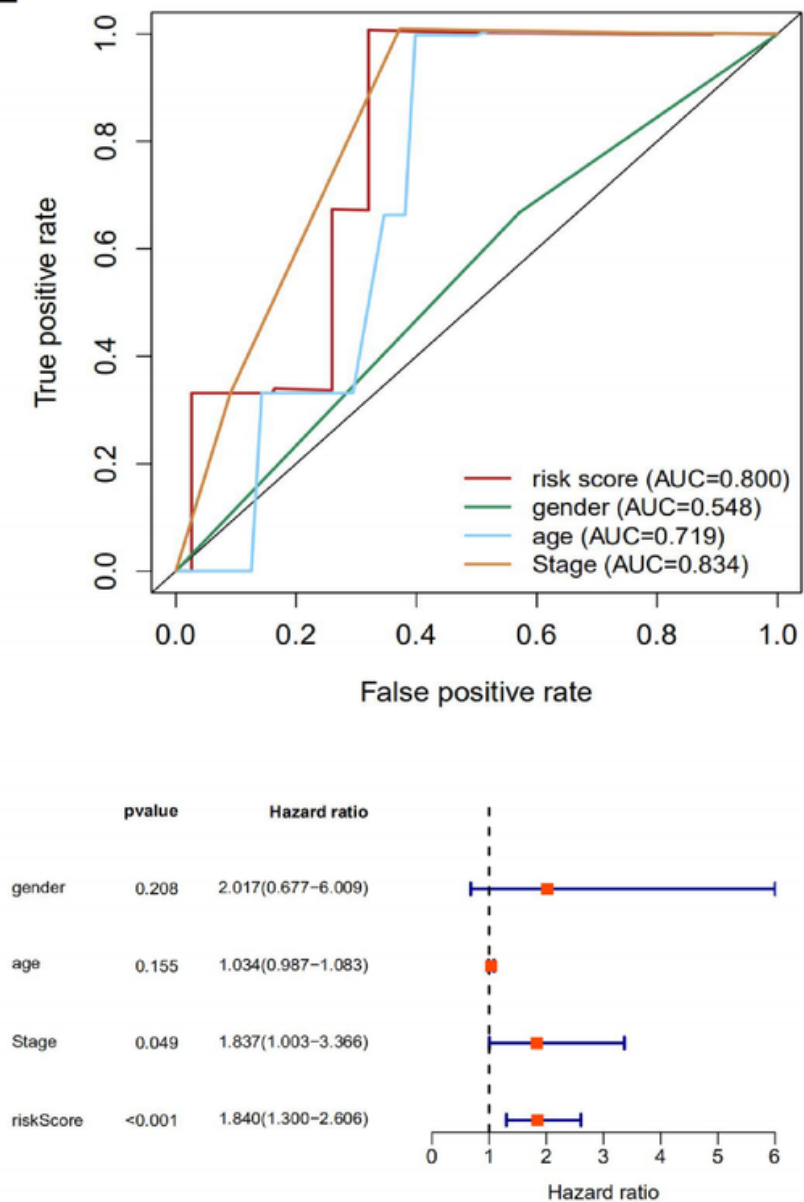

Figure 3

Independent prognostic ability of the model A Risk score distribution; B Survival status scatter plot; C Univariate analysis; D Multivariate Cox analyses; E Time-dependent receiver operating characteristic (ROC) curve analyses of the prognostic variables 
A

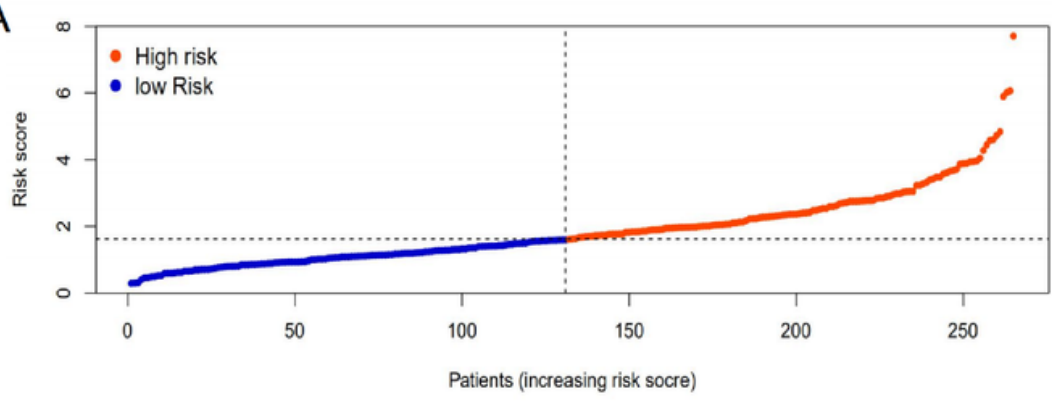

B

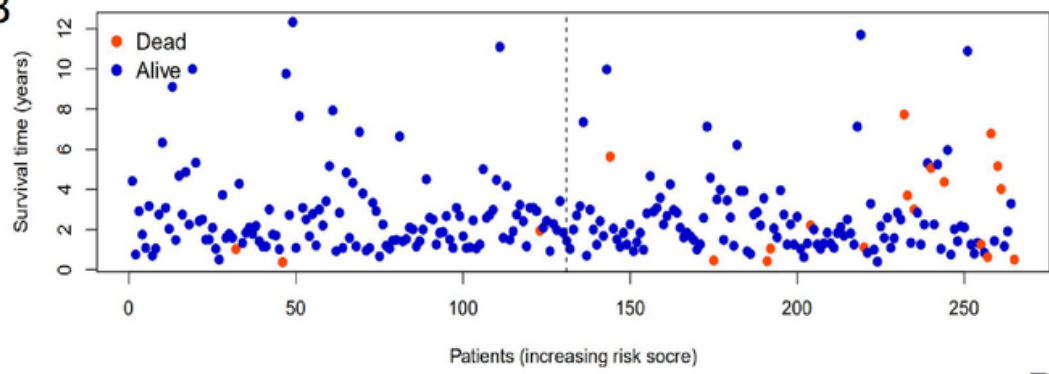

C
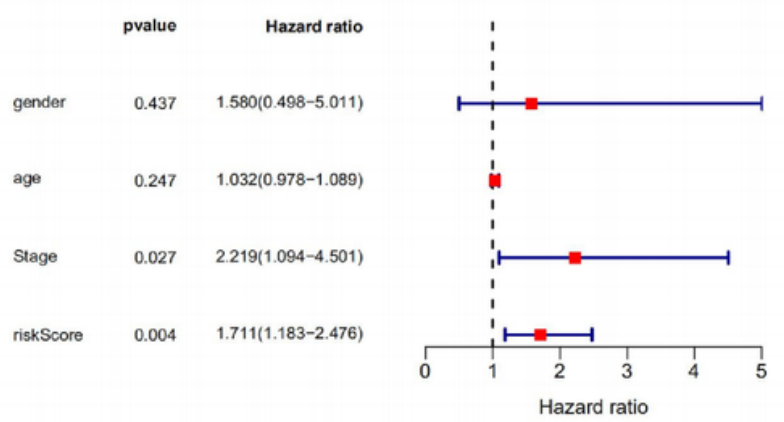

E
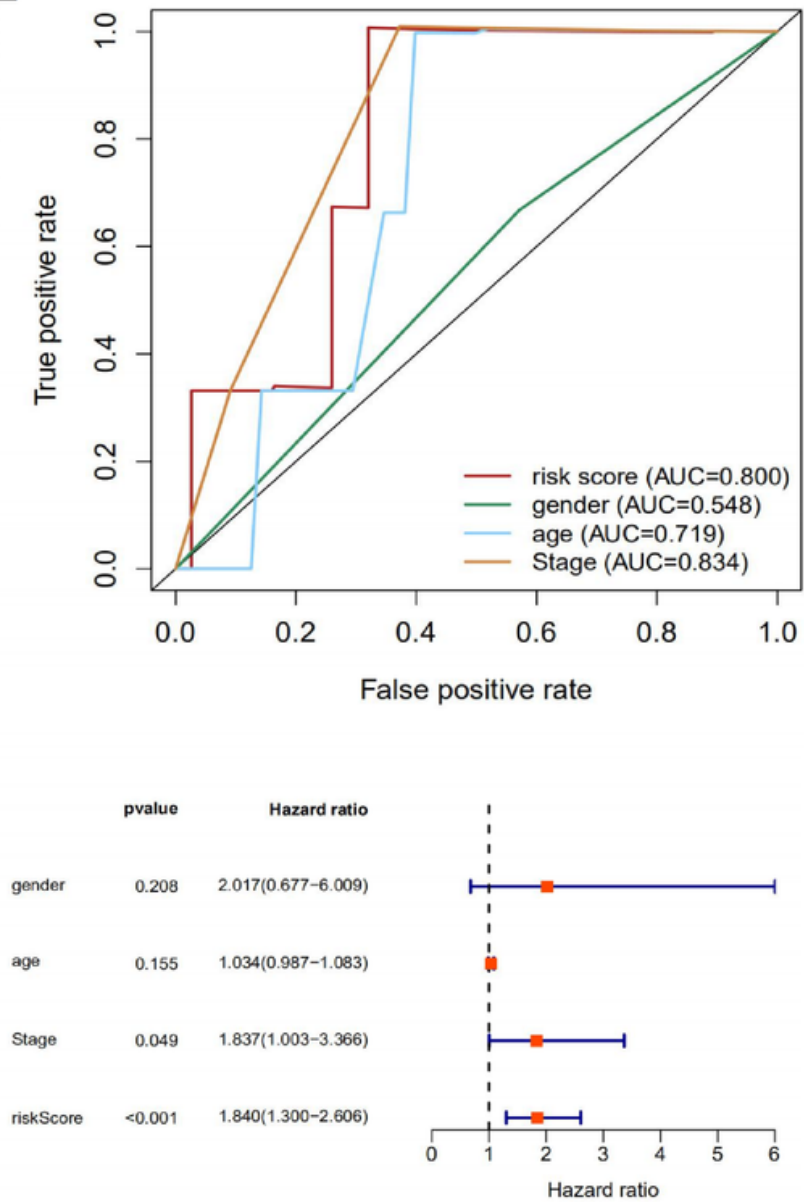

Figure 3

Independent prognostic ability of the model A Risk score distribution; B Survival status scatter plot; C Univariate analysis; D Multivariate Cox analyses; E Time-dependent receiver operating characteristic (ROC) curve analyses of the prognostic variables 

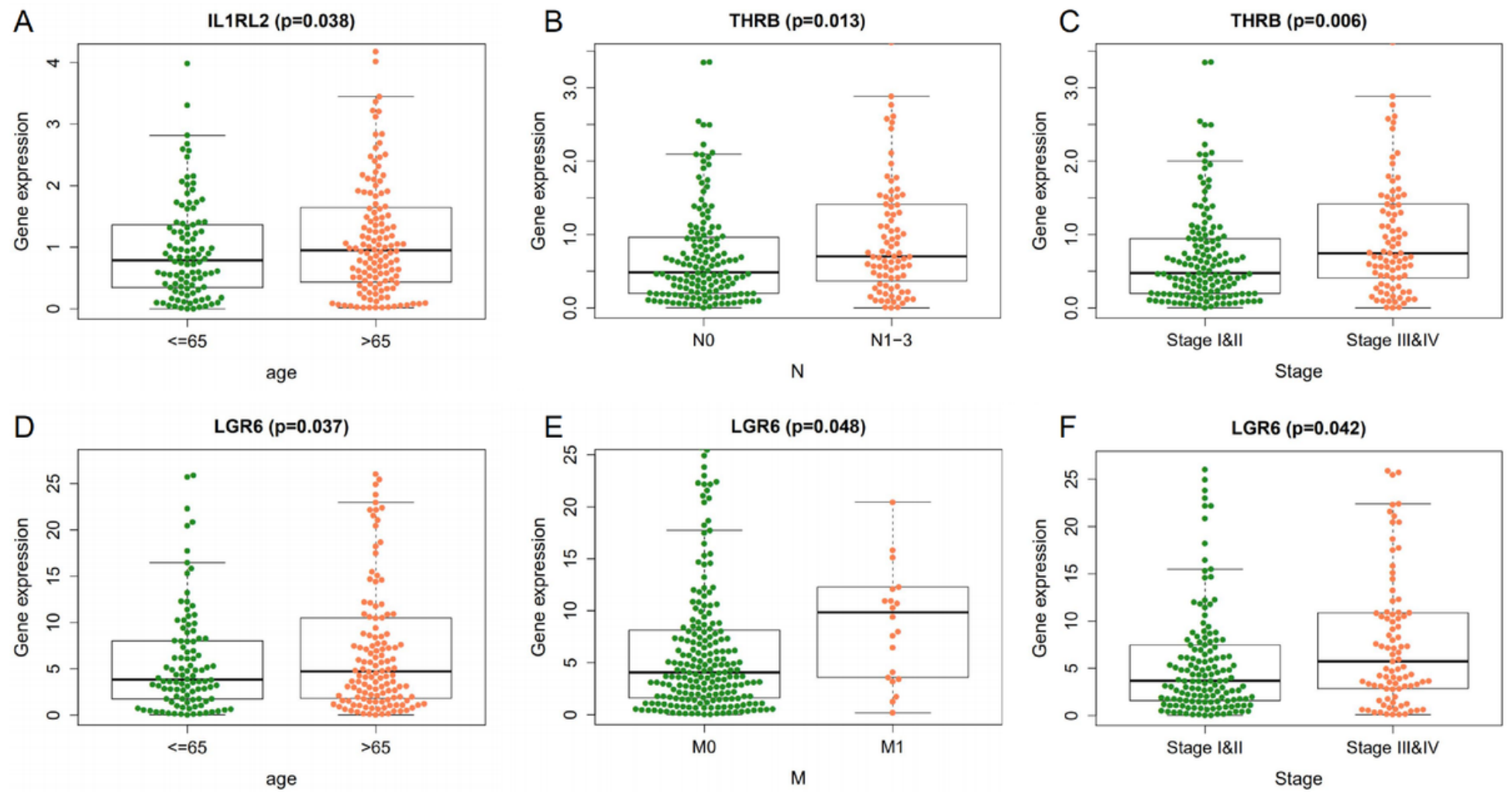

Figure 4

Correlation between genes in the model and clinical characteristics A Relationship between IL1RL2 and age; B Relationship between THRB and N; C Relationship between THRB and pathological stage; D Relationship between LGR6 and age; E Relationship between LGR6 and M; F Relationship between LGR6 and pathological stage
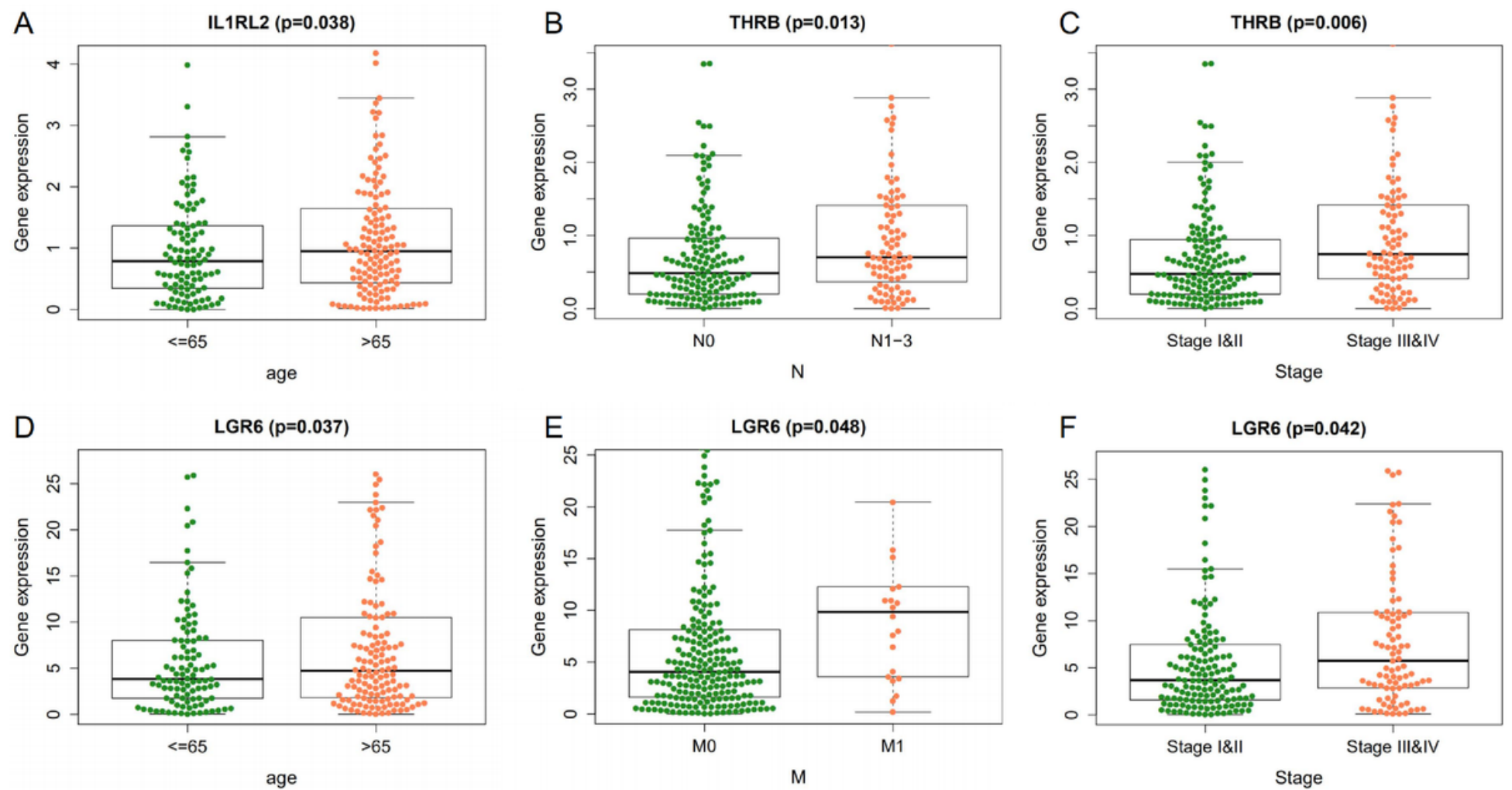
Figure 4

Correlation between genes in the model and clinical characteristics A Relationship between IL1RL2 and age; B Relationship between THRB and N; C Relationship between THRB and pathological stage; D Relationship between LGR6 and age; E Relationship between LGR6 and M; F Relationship between LGR6 and pathological stage
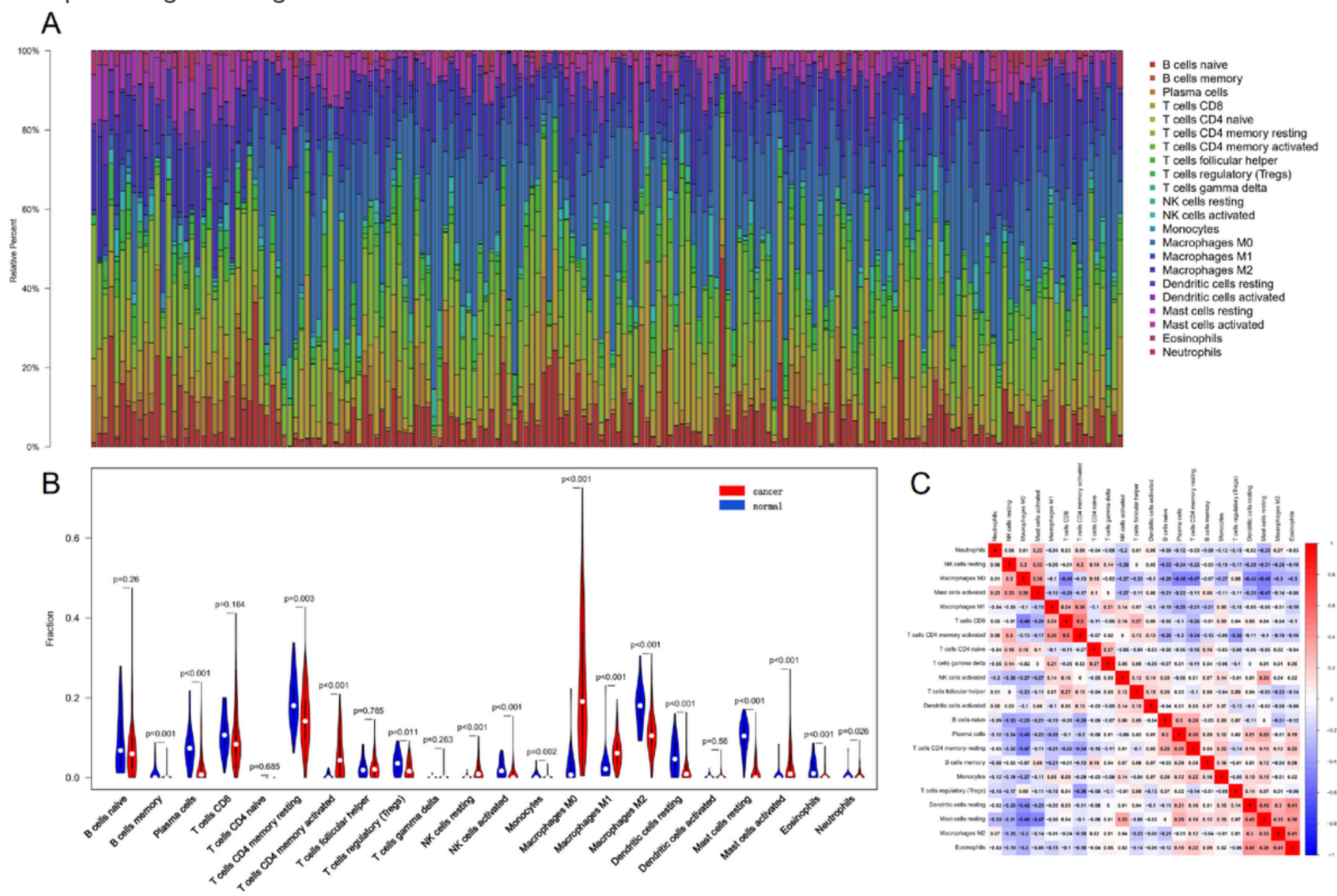

Figure 5

Immune cells infiltration of patients A Infiltration of 22 kinds of immune cells; B Immune cells level in normal and cancer tissues; C Correlations between different immune cells 

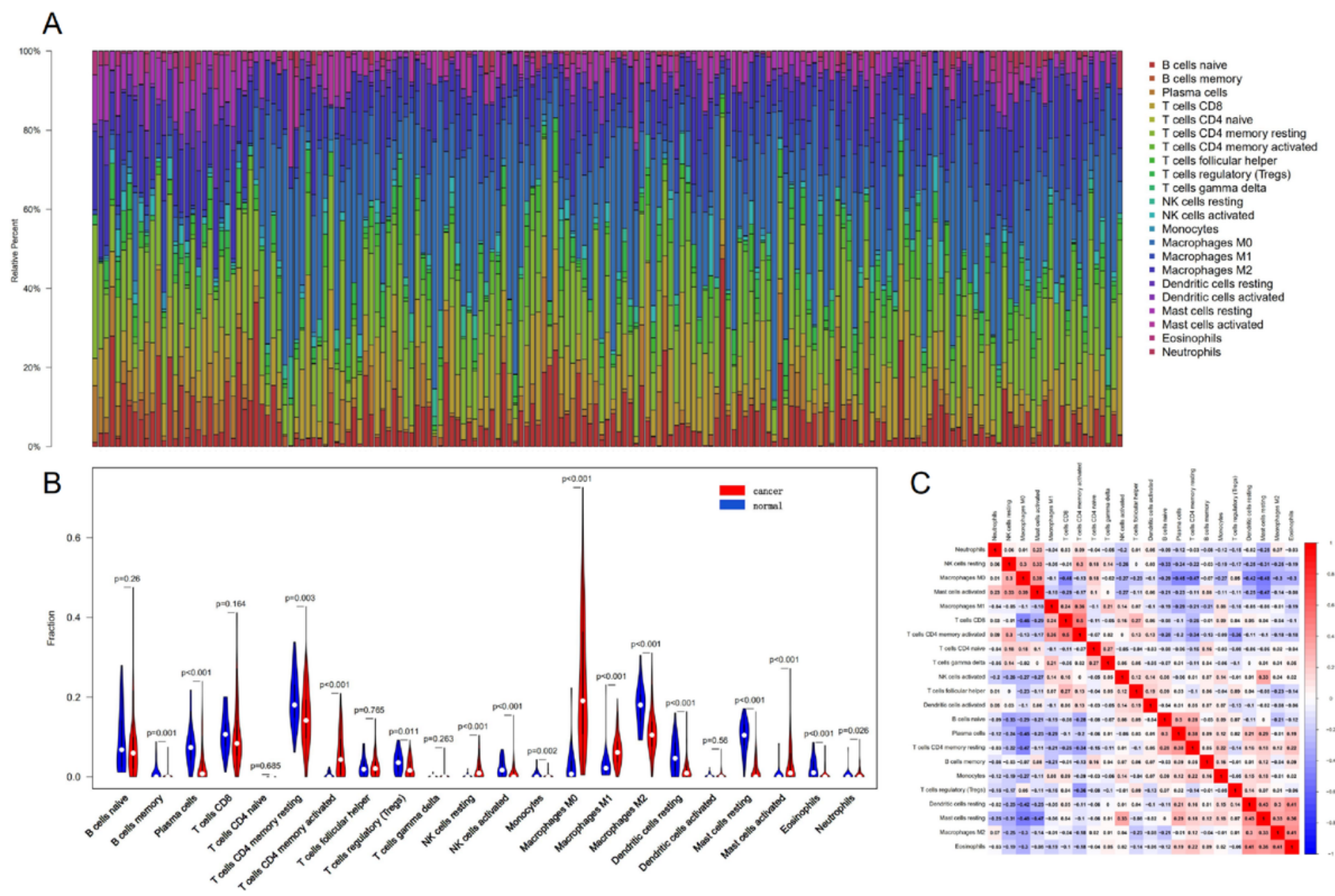

Figure 5

Immune cells infiltration of patients A Infiltration of 22 kinds of immune cells; B Immune cells level in normal and cancer tissues; $C$ Correlations between different immune cells 
A

Cor $=0.247(p=0.013)$
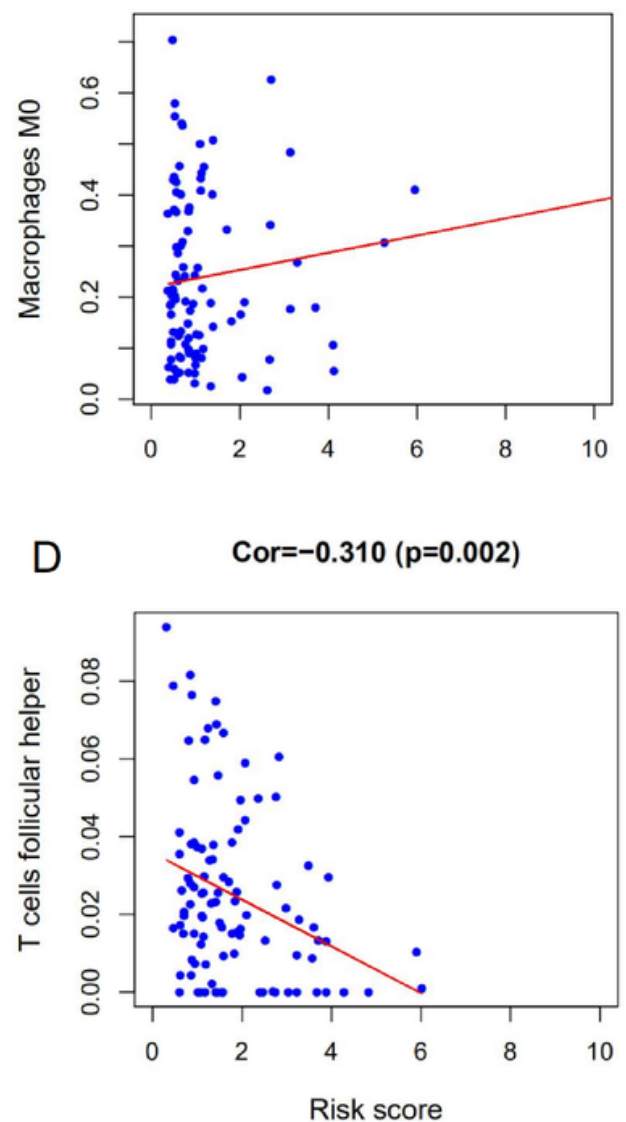

B

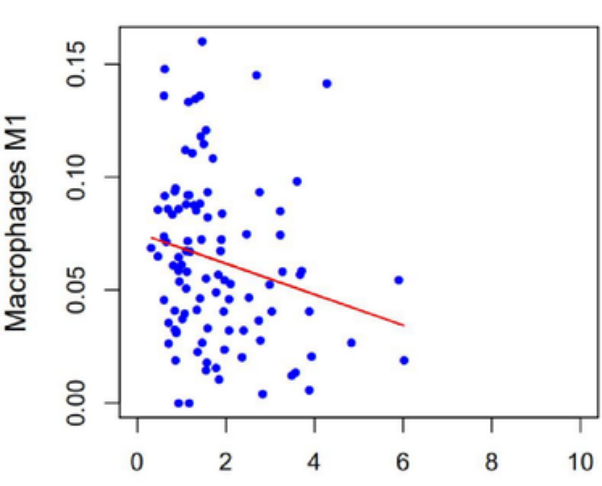

Risk score

E

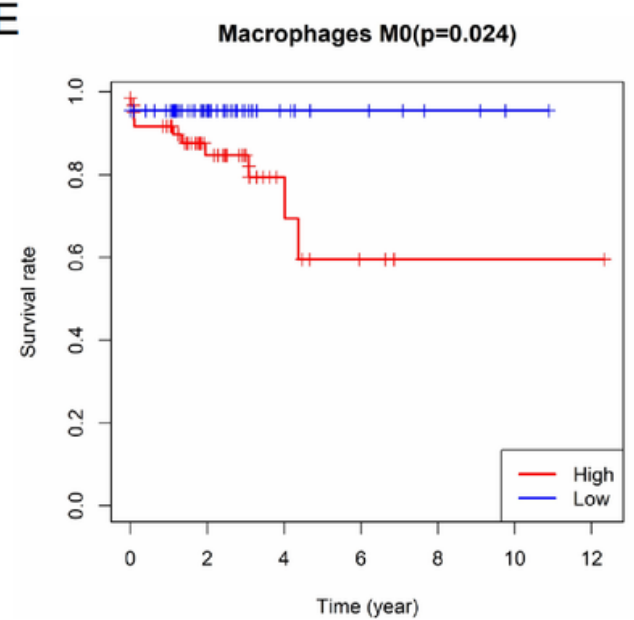

C

Cor $=-0.206(p=0.039)$

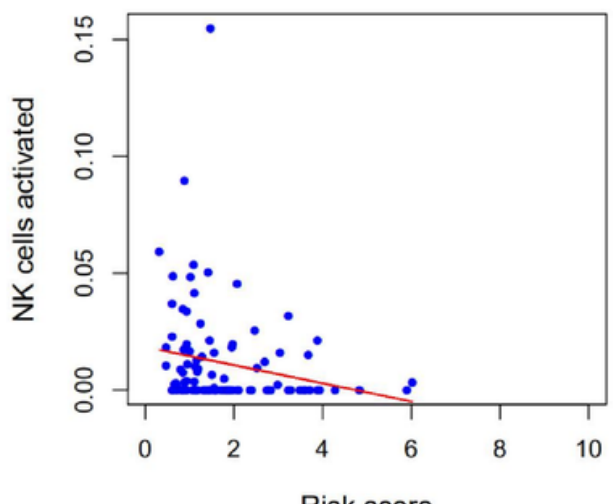

Risk score

$\mathrm{F}$
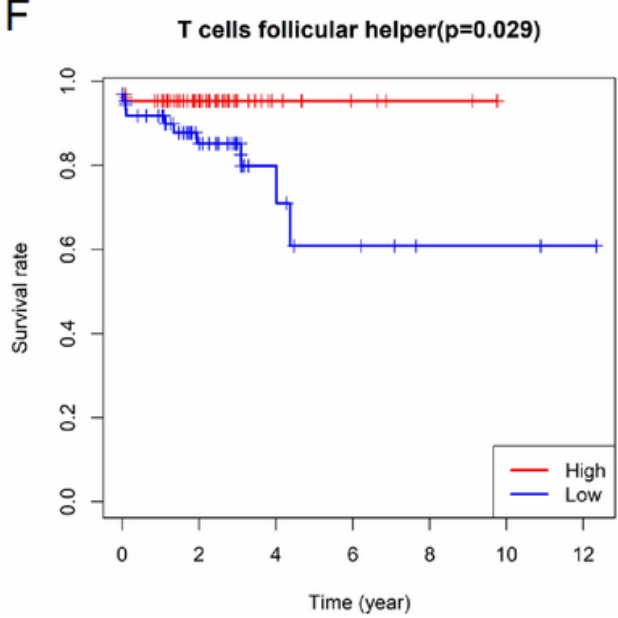

Figure 6

Relationship between model and immune cell infiltration A Macrophages M0; B Macrophages M1; C NK cells activated; D T cells follicular helper; E Survival analysis of Macrophages M0; F Survival analysis of T cells follicular helper 
A

Cor $=0.247(p=0.013)$

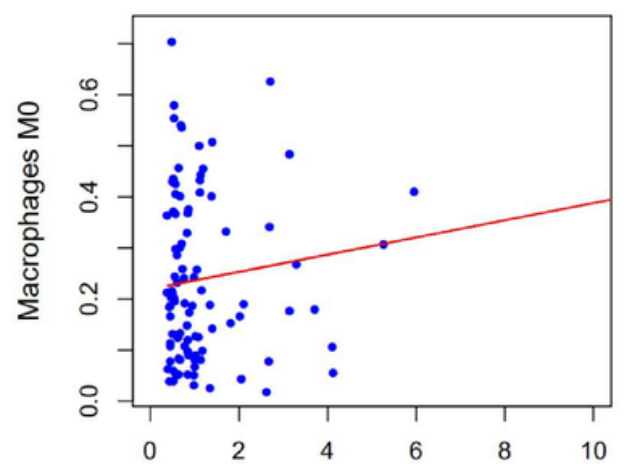

D

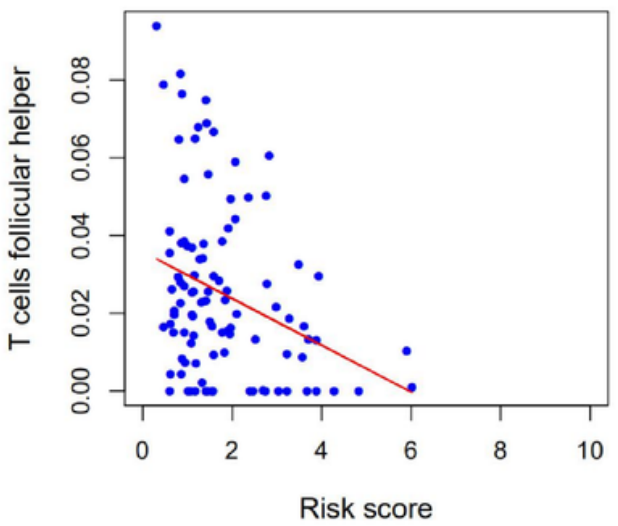

B

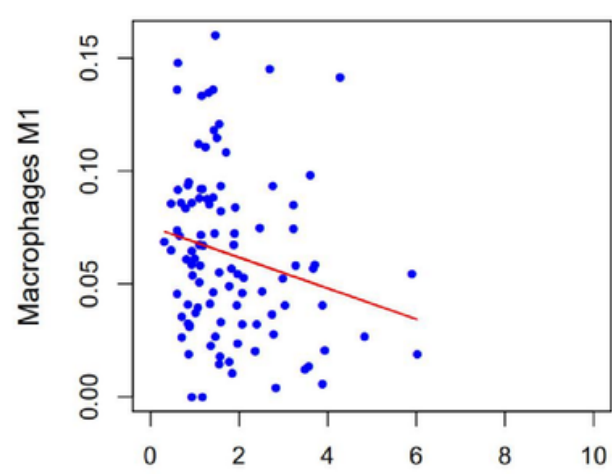

Risk score

E

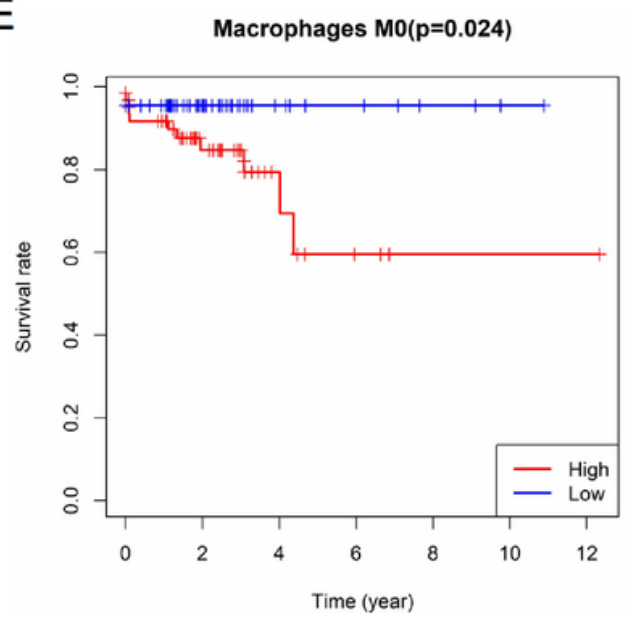

C

Cor $=-0.206(p=0.039)$

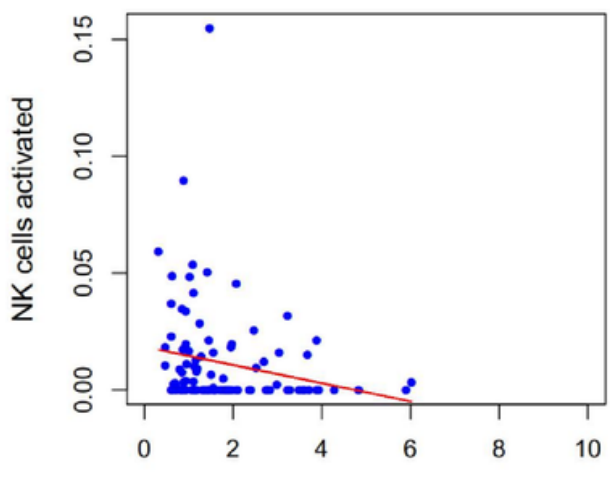

Risk score

F
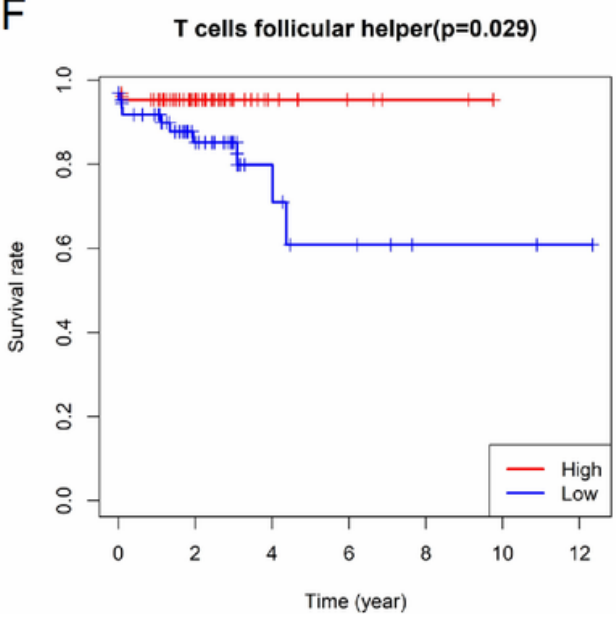

Figure 6

Relationship between model and immune cell infiltration A Macrophages M0; B Macrophages M1; C NK cells activated; D T cells follicular helper; E Survival analysis of Macrophages M0; F Survival analysis of T cells follicular helper 